\title{
Efficacy of elective nodal irradiation in skin squamous cell carcinoma of the face, ears, and scalp
}

\author{
Justin Wray ${ }^{1}$, Robert J. Amdur ${ }^{1 *}$, Christopher G. Morris', John Werning ${ }^{2}$ and William M. Mendenhall ${ }^{1}$
}

\begin{abstract}
Background: In patients at high risk for regional node metastasis from squamous cell carcinoma (SCC) of the skin of the face, ear, or scalp, radiotherapy to the regional nodes is an alternative to parotid or neck surgery. Data on the efficacy of elective nodal radiotherapy in this setting are scarce such that there is no publication specifically addressing the subject. The purpose of our study is to fill this void in the skin cancer literature.

Methods: This is a single-institution study of outcomes following elective nodal radiotherapy in 71 consecutively treated adults with SCC of the face, ears, or scalp. Primary site stage distribution per the American Joint Committee on Cancer, $7^{\text {th }}$ Edition, was as follows: T1, $15 \% ; T 2,34 \% ; T 3,1 \%$; and T4, $50 \%$. Other disease characteristics included the following: clinical perineural invasion, $13 \%$; pathological perineural invasion, 78 \%; recurrent disease, 32 \%; and positive or close margin, $67 \%$. The median radiation dose to the first- and second-echelon nodal area was $50 \mathrm{~Gy}$. Acute and late toxicity were graded per the Common Terminology Criteria for Adverse Events, version 4.0. Regional control was assessed using the Kaplan-Meier product limit method.
\end{abstract}

Results: Median followup was 4.5 years for all patients. The actuarial regional control rate at 5 years was $96 \%$. There were no $(0 \%)$ grade 3 or higher complications from elective nodal irradiation.

Conclusions: Elective nodal irradiation in patients with high-risk SCC of the face, ears and scalp is safe and effective.

Keywords: Skin cancer, Head and neck, Radiotherapy, Elective nodal radiotherapy, Outcomes

\section{Background}

Major risk factors found at the primary site that predispose to nodal metastasis from squamous cell carcinoma (SCC) of the skin include the following: tumor diameter > $2 \mathrm{~cm}$, tumor thickness $>5 \mathrm{~mm}$, poor differentiation, tumor location within ear, age $>70$ years, perineural invasion (PNI), history of recurrence, and immunosuppression $[1,2]$. Elective neck surgery often including parotidectomy effectively prevents regional node recurrence, but the morbidity of surgery in this setting is frequently substantial $[3,4]$. An alternative to elective neck surgery is elective nodal irradiation (ENI) since many of the cancers in which neck management is indicated

\footnotetext{
* Correspondence: amdurr@shands.ufl.edu

${ }^{1}$ Department of Radiation Oncology, University of Florida, 2000 SW Archer Road, PO Box 100385, Gainesville, FL, USA

Full list of author information is available at the end of the article
}

also present with indications for primary or adjuvant radiation therapy $(\mathrm{RT})$ to the primary site.

There is no study that focuses on ENI in SCC of the skin of the face, head, or neck. A few publications present subset analyses that address the ENI issue to some degree, but to our knowledge, none of these studies describe overall risk factors in the ENI group, the technical details of ENI, the actuarial risk of neck control following ENI, or toxicity related to ENI [5-7]. The purpose of this study is to fill this void in the skin cancer literature.

\section{Methods \\ Under the approval of the University of Florida Institu- tional Review Board, we reviewed the medical records of 71 patients with SCC of the skin of the face, ears, or scalp treated at our institution with RT to the primary site and regional lymphatics between 1985 and 2012.}


The year 1985 marks when our institution routinely began using axial computed tomography (CT) or magnetic resonance imaging (MRI) to stage head and neck cancer patients. This study is limited to patients who received elective nodal radiotherapy, meaning there was no clinical or radiographic evidence of nodal metastasis and no history of surgery to the regional lymphatics. Throughout the 28-year period of this study it was the policy in our department to add ENI in patients with recurrent tumors, poor differentiation, perineural invasion, tumor size greater than $2 \mathrm{~cm}$, positive margin, or immunosuppression. This study is limited to situations wherein a major change in treatment volume was made specifically to electively irradiate the regional nodes. Not included in this study are cases wherein inclusion of nodal tissue was only accomplished by enlarging the primary field a small amount.

ENI was delivered to the first-echelon nodal region in all cases in this study. The distribution of first-echelon nodal areas among our cohort was as follows: parotid, $75 \%$; facial, $37 \%$; retroauricular, $28 \%$; occipital, $10 \%$; and cervical levels 1 and 2, $8 \%$.

Table 1 lists the relevant patient and tumor characteristics. Clinical PNI was defined as a cranial nerve deficit on physical examination and/or visible tumor in a major cranial nerve branch on CT or MRI scan.

In addition to the information summarized in Table 1, distribution of primary site location was as follows: ear pinna (13\%), lateral cheek (11\%), temple (11\%), medial cheek (10\%), nose (10\%), external auditory canal (9\%), forehead (9\%), postauricular (7\%), posterior scalp (7\%), anterior scalp (5\%), upper lip vermillion (4\%), upper lip skin (3\%), and lower lip skin (1\%).

All patients in this study were clinically node-negative based on physical examination and $85 \%$ by axial CT or MR scan. Primary site stage distribution per the American Joint Committee on Cancer, $7^{\text {th }}$ Edition [8], was as follows: T1, $15 \%$; T2, $34 \%$; T3 1 \%; and T4 $50 \%$. Patients were also staged according to a recently proposed, potentially more relevant staging system employing risk factors (poor differentiation, PNI, tumor diameter $\geq 2 \mathrm{~cm}$, and invasion of subcutaneous fat) [6]. Stage distribution per this proposed system was as follows: T1 (0 risk factor), $6 \%$; T2A ( 1 risk factor), $34 \%$; T2B (2-3 risk factors), $43 \%$; and T3 (4 risk factors), $17 \%$.

Based on the data from Mendenhall [1], O'Hara [2], and Pahlajani [6], we estimate that the great majority of patients in our study had at least a $10 \%$ chance of subclinical disease in the regional lymphatics. Table 2 summarizes the details of RT. In brief, the median radiation dose to the primary site was 65 Gy (range, 38$74 \mathrm{~Gy}$ ), the median radiation dose to the first-echelon nodal area was 50 Gy (range, 38-74 Gy), and the median radiation dose to the other nodal areas was 50 Gy
Table 1 Patient characteristics $(\mathrm{N}=71)$

\begin{tabular}{|c|c|}
\hline Characteristics & No. of patients (\%) \\
\hline \multicolumn{2}{|l|}{ Sex } \\
\hline Male & $48(68)$ \\
\hline Female & $23(32)$ \\
\hline \multicolumn{2}{|l|}{ Race or ethnicity } \\
\hline White & $69(97)$ \\
\hline Black & $1(1.5)$ \\
\hline Hispanic & $1(1.5)$ \\
\hline Immunosuppressed & $6(8.5)$ \\
\hline Adjuvant RT (post-op) without visible tumor & $53(75)$ \\
\hline Visible tumor present at time of RT & $18(25)$ \\
\hline Recurrent after curative-intent surgery & $23(32)$ \\
\hline Clinical perineural invasion & $9(13)$ \\
\hline Cancer touches midline & $17(24)$ \\
\hline \multicolumn{2}{|l|}{ Radiological and Pathological Risk Factors } \\
\hline$>2 \mathrm{~cm}$ primary & $36(51)$ \\
\hline$>5 \mathrm{~mm}$ thickness & $24(44)$ \\
\hline$>2 \mathrm{~mm}$ invasion & $17(31)$ \\
\hline Subcutaneous fat invasion & $10(18)$ \\
\hline Perineural invasion in pathology report & $45(76)$ \\
\hline Lymph-vascular space invasion & $8(14)^{\mathrm{a}}$ \\
\hline $\begin{array}{l}\text { Bone invasion in pathology or imaging } \\
\text { report }\end{array}$ & $8(12)^{b}$ \\
\hline $\begin{array}{l}\text { Cartilage invasion in pathology or } \\
\text { imaging report }\end{array}$ & $6(9)^{b}$ \\
\hline \multicolumn{2}{|l|}{ Margin status } \\
\hline Positive margin & $31(56)^{c}$ \\
\hline Negative margin & $18(33)^{c}$ \\
\hline Close $(<5 \mathrm{~mm})$ margin & $6(11)^{c}$ \\
\hline \multicolumn{2}{|l|}{ Differentiation } \\
\hline Well differentiated & $15(21)$ \\
\hline Moderately differentiated & $14(20)$ \\
\hline Poorly differentiated & $25(35)$ \\
\hline Undifferentiated & $2(3)$ \\
\hline Not Reported & $15(21)$ \\
\hline Nodes negative by $\mathrm{CT}$ or MR scan & $60(85)$ \\
\hline Characteristics & Median value (range) \\
\hline Age & 69 years (33-95) \\
\hline Days from previous treatment to recurrence & 344 days (28-1078) \\
\hline
\end{tabular}

Notes: ${ }^{2}$ The percentage of patients was calculated with a total of 59 patients. ${ }^{\mathrm{b}}$ The percentage of patients as calculated with a total of 68 patients. 'The percentage of patients was calculated with a total of 55 patients. Abbreviations: $\mathrm{RT}$, radiation therapy; $\mathrm{CT}$, computed tomography; MR, magnetic resonance

(range, 30-60 Gy). Three patients received concurrent chemotherapy for advanced disease with carboplatin and taxol (1 patient), carboplatin alone (1 patient) or cisplatin alone (1 patient). 
Table 2 Radiation therapy $(\mathrm{N}=71)$

\begin{tabular}{|c|c|}
\hline Treatment Characteristics & Median value (range) \\
\hline Radiation therapy duration (days) & 44 days ( 16 to 55 ) \\
\hline Primary site dose & 65 Gy (38 to 74) \\
\hline $1^{\text {st }}$ echelon node station dose & $50 \mathrm{~Gy}$ (38 to 74 ) \\
\hline Other node station dose & 50 Gy (30 to 60) \\
\hline Treatment Characteristic & No. of patients (\%) \\
\hline \multicolumn{2}{|c|}{ Primary site radiation therapy modality } \\
\hline Orthovoltage (250-kV) & $15(21 \%)$ \\
\hline Electron & $21(30 \%)$ \\
\hline Cobalt-60 & $1(1 \%)$ \\
\hline 4- to 6-MV photon & $20(28 \%)$ \\
\hline Mixed photon-electron & $14(20 \%)$ \\
\hline \multicolumn{2}{|c|}{ First-echelon node radiation therapy modality } \\
\hline Orthovoltage (250 kV) & $11(15 \%)$ \\
\hline Electron & $24(34 \%)$ \\
\hline Cobalt-60 & $0(0 \%)$ \\
\hline 4- to 6-MV photon & $24(34 \%)$ \\
\hline Mixed photon-electron & $12(17 \%)$ \\
\hline \multicolumn{2}{|c|}{ First-echelon node radiation therapy technique } \\
\hline En-face Electron & $24(34 \%)$ \\
\hline En-face Mixed Electron-Photon & $12(17 \%)$ \\
\hline En-face Orthovoltage & $11(15 \%)$ \\
\hline $6 \mathrm{MV}$ Photon wedge pair & $14(20 \%)$ \\
\hline $6 \mathrm{MV}$ IMRT & $7(10 \%)$ \\
\hline Anterior 6MV Photon & $3(4 \%)$ \\
\hline \multicolumn{2}{|c|}{$\begin{array}{l}\text { Radiation therapy modality for other nodal } \\
\text { stations }\end{array}$} \\
\hline Orthovoltage (250 kV) & $0(0)^{\mathrm{a}}$ \\
\hline Electron & $19(32)^{a}$ \\
\hline Cobalt-60 & $4(7)^{a}$ \\
\hline 4- to 6-MV photon & $34(56)^{\mathrm{a}}$ \\
\hline Mixed photon-electron & $3(5)^{a}$ \\
\hline Concurrent chemotherapy & $3(4)$ \\
\hline
\end{tabular}

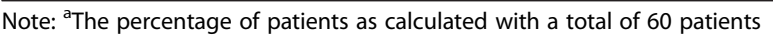

\section{Statistical analyses}

The efficacy endpoint in this study is regional control, which we define as freedom from tumor recurrence in a lymph node. All statistical analyses were performed using SAS and JMP software (SAS Institute, Cary, NC). Regional control was assessed using the Kaplan-Meier product limit method. The log-rank test statistic was used to detect any statistically significant differences between strata of selected explanatory variables.

The toxicity endpoint in this study is an effect that could be related to elective nodal RT. We graded acute and late toxicities with the most recent version of the National Cancer Institute Common Terminology Criteria for Adverse
Events, version 4.0 (CTCAE v4.0) [7]. In this retrospective analysis we were not able to accurately report minor (grade 1 or 2) toxicities. For this reason our report is limited to grade 3 to 5 toxicities.

\section{Results}

\section{Follow-up}

The median follow-up after the last day of RT was 4.5 years for all patients (range, $0.8-22.5$ years), and 6.0 years for living patients (range, 1.9-22.5 years).

Table 3 Characteristics of the 2 patients with isolated nodal recurrence related to elective nodal irradiation

\begin{tabular}{|c|c|c|}
\hline Characteristics & Patient 1 & Patient 2 \\
\hline Age (years) & 64 & 75 \\
\hline Subsite & Pinna & Temple \\
\hline First echelon treated & Parotid & Parotid \\
\hline Extended elective nodal irradiation & $\begin{array}{l}\text { Facial; cervical } \\
1 \mathrm{~b} \text { and } 2\end{array}$ & Cervical 2 \\
\hline Sex & Male & Male \\
\hline Race & White & White \\
\hline $\begin{array}{l}\text { American Joint Committee on } \\
\text { Cancer, 7th ed., stage }\end{array}$ & T4 & $\mathrm{T} 1$ \\
\hline $\begin{array}{l}\text { Proposed } 2013 \text { Journal of American } \\
\text { Medical Association stage }\end{array}$ & $\mathrm{T} 2 \mathrm{~A}$ & $\mathrm{~T} 2 \mathrm{~A}$ \\
\hline Axial imaging performed & Yes & Yes \\
\hline Immunosuppressed & Yes & No \\
\hline Cancer touches midline & No & No \\
\hline Clinical perineural invasion & No & No \\
\hline Pathological perineural invasion & Yes & No \\
\hline$>2 \mathrm{~cm}$ primary & No & No \\
\hline$>5 \mathrm{~mm}$ thickness & No & No \\
\hline$>2 \mathrm{~mm}$ invasion & No & No \\
\hline Invaded subcutaneous fat & No & No \\
\hline Lymphovascular space invasion & Yes & No \\
\hline $\begin{array}{l}\text { Bone invasion on pathology or } \\
\text { imaging }\end{array}$ & No & No \\
\hline $\begin{array}{l}\text { Cartilage invasion on pathology } \\
\text { or imaging }\end{array}$ & No & No \\
\hline Recurrent after curative-intent surgery & Yes & Yes \\
\hline $\begin{array}{l}\text { Days from first surgery to } \\
\text { radiotherapy start }\end{array}$ & 244 & 323 \\
\hline Positive or close margin & Yes & No \\
\hline Histology & Moderate & Poor \\
\hline $\begin{array}{l}\text { Adjuvant (postoperative) without } \\
\text { visible tumor }\end{array}$ & Yes & Yes \\
\hline Primary (Gy) & 60 (once daily) & 74 (twice daily) \\
\hline 1st Echelon (Gy) & 46 (once daily) & 74 (twice daily) \\
\hline Rest (Gy) & 50 (once daily) & 46 (once daily) \\
\hline
\end{tabular}




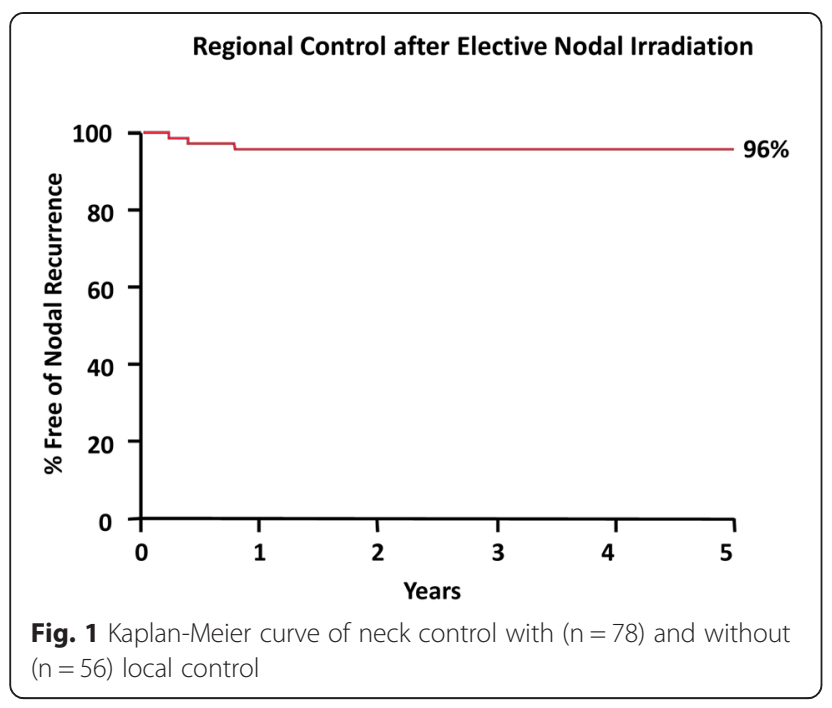

\section{Regional control after elective nodal irradiation}

The rate of isolated nodal recurrence in an area treated with ENI was 2 of 71 (2.8\%). Table 3 summarizes the details of these two cases.

In addition to 2 isolated nodal recurrences in areas of ENI, 2 patients experienced nodal recurrence that we do not attribute to ENI. One patient developed a nodal recurrence in a contralateral level 1 node outside of the RT target volume and would not have been removed through an elective neck dissection; therefore, we do not consider this event a failure of ENI compared to the surgical alternative. An additional patient simultaneously recurred in the primary site and regional node, which suggests that the nodal recurrence could be a secondary event related to metastasis from the primary site recurrence rather than failure of the ENI to sterilize subclinical disease.

Fifteen patients recurred at the primary site (of these, 1 had a simultaneous nodal recurrence in the first-echelon nodes and 14 never developed a nodal recurrence throughout the follow-up period). The most reliable measure of efficacy of ENI is the regional recurrence rate in patients who received ENI but remained continuously free of recurrence at the primary site and the area which received ENI: In our study, 2 of 56 patients recurred in this area $(3.6 \%)$.

Figure 1 is an actuarial plot of regional control following ENI. After rounding off to the nearest whole number, the actuarial 5-year rate of continuous freedrom from a nodal recurrence (not including surgical salvage) was $96 \%$ for both the overall group of 71 patients and for the 56 patients without a primary site recurrence.

\section{Time to nodal recurrence after Elective Nodal Irradiation}

All 4 nodal recurrences presented within 1 year of completing RT.

\section{Regional control including surgical salvage of nodal recurrence}

In 3 of the 4 patients with a nodal recurrence, salvage neck dissection was performed with curative intent (and the patient who simultaneously recurred at the primary site was also treated with resection of the primary site). Salvage surgery was successful in 2 of the 3 patients who underwent salvage attempt based on no evidence of cancer at last follow-up (at least 1 year after salvage

Table 4 First echelon nodal volumes treated and the techniques used.

\begin{tabular}{lllll}
\hline Nodal Area (\%) & Most Common First Echelon & $\begin{array}{l}\text { Most Common Radiation } \\
\text { Technique Used (\%) }\end{array}$ & $\begin{array}{l}\text { 2nd Most Common Radiation } \\
\text { Technique Used (\%) }\end{array}$ & $\begin{array}{l}\text { 3rd Most Common Radiation } \\
\text { Technique Used (\%) }\end{array}$ \\
\hline Ear Pinna (13) & Parotid (100) & Photons (44) & Electrons (22) & Mixed (22) \\
Lateral Cheek (11) & Parotid (100) & Photons (38) & Mixed (38) & Electrons (13) \\
Medial Cheek (10) & Parotid (100) & Photons (29) & Electrons (29) & Mixed (29) \\
Temple (11) & Parotid (100) & Electrons (75) & Mixed (13) & NA \\
Nose (10) & Facial (71) & Orthovoltage (60) & Photons (40) & Mixed (17) \\
External Auditory Canal (9) & Parotid (100) & Photons (67) & Electrons (17) & Mixed (20) \\
Forehead (9) & Parotid (83) & Electrons (100) & NA \\
Post-auricular (7) & Retro-auricular (100) & Photons (40) & Mixed (50) & Photons (25) \\
Posterior Scalp (7) & Occipital (80) & Photons (50) & Electrons (25) & NA \\
Anterior Scalp (5) & Post-auricular (80) & Mixed (50) & NA & NA \\
Upper lip vermillion (4) & Bilateral Cervical (66) & Photons (100) & NA & Orthovoltage (50) \\
Upper lip skin (3) & Facial (100) & Photons (50) & NA & NA \\
Lower lip skin (1) & Ipsilateral Cervical (100) & Photons (100) & &
\end{tabular}

NA, not available

Mixed: includes the use of both electrons, orthovoltage and photons to achieve coverage of the indicated nodal area 
surgery). In the remaining patient, salvage surgery was not attempted because of the extent of adenopathy and underlying medical problems.

\section{Toxicity of Elective Nodal Irradiation}

There were no $(0 \%)$ grade 3 or higher toxicity events that could be related to ENI.

\section{Discussion}

The primary value of this series is that it is the first study to focus on the efficacy of ENI in a general population of patients with SCC of the skin of the head and neck, for whom this issue is most pertinent. We know of only 3 other studies with data on this subject and none include details about overall risk factors, ENI target areas, ENI dose, or location of recurrence relative to ENI $[5,9,10]$.

The 1987 study by Mendenhall et al from our department reported outcomes of patients treated with radiotherapy for gross disease at the primary site [9]. Almost half the patients had basal cell carcinoma and most were not staged with cross-sectional imaging. The only data relevant to our discussion is that, with ENI, 8 of 10 patients with recurrent SCC remained continuously free of a nodal recurrence.

The 2005 study by Moore and colleagues reports freedom from recurrence in 4 of 5 patients treated with ENI, but it is unclear if the sole recurrence was local, regional, or both [5]. In patients who present with parotid gland metastases, cervical ENI has been previously shown to decrease neck failures from $50 \%$ in observed patients to $0 \%$ in those treated with ENI [11]. The more recent series from our department authored by Balamucki and colleagues focuses on outcomes of patients with clinical or incidental PNI from basal or squamous cell carcinoma of the skin [10]. With ENI, the actuarial rate of regional control at 5 years was $96 \%$ in patients with clinical PNI and $100 \%$ in patients with incidental PNI.

\section{Conclusions}

The experience reported in this paper supports the conclusion that, in patients with SCC of the skin of the face, pinna, external auditory canal, or scalp, the rate of nodal recurrence and toxicity is very low in areas that receive at least 50 Gy of ENI. The implication of this conclusion is that, in patients similar to the study population, clinicians should consider ENI when the risk of subclinical disease in the regional lymphatics is considered to be high. This recommendation is supported by the 2015 guidelines from the National Comprehensive Cancer Center Network which include ENI (50 Gy at 2 Gy per fraction) in patients with SCC of the skin who are "at risk for subclinical disease" and have not undergone elective neck dissection [12].

The nodal areas we treated in this study are listed in Table 4. As this study was limited to patients who received ENI, the data does not inform the question of indications for elective treatment of the regional nodes, how an approach using ENI compares to elective neck dissection, or observation with treatment reserved for salvage of nodal recurrence.

\section{Competing interests}

The authors declare that they have no competing interests.

\section{Authors' contributions}

Dr. JW collected and interpreted the data and drafted the manuscript; Dr. RJA conceptualized the study, collected and interpreted the data, and contributed to the writing of the manuscript; CGM collected and interpreted the data, conducted the statistical analysis, and contributed to the writing of the manuscript; Dr. JW collected the data and contributed to the writing of the manuscript; Dr. WMM collected the data and contributed to the writing of the manuscript. All authors read and approved the final manuscript.

\section{Acknowledgments}

We would like to thank Jessica Kirwan for preparing and editing the manuscript for publication.

\section{Author details}

${ }^{1}$ Department of Radiation Oncology, University of Florida, 2000 SW Archer Road, PO Box 100385, Gainesville, FL, USA. ²Department of Otolaryngology, University of Florida, Gainesville, FL, USA.

Received: 2 July 2015 Accepted: 11 September 2015

Published online: 21 September 2015

\section{References}

1. Mendenhall WM, Amdur RJ, Hinerman RW, Cognetta AB, Mendenhall NP. Radiotherapy for cutaneous squamous and basal cell carcinomas of the head and neck. Laryngoscope. 2009;119(10):1994-9.

2. O'Hara J, Ferlito A, Takes RP, Rinaldo A, Strojan P, Shaha AR, et al. Cutaneous squamous cell carcinoma of the head and neck metastasizing to the parotid gland-a review of current recommendations. Head Neck. 2011;33(12):1789-95.

3. Cappiello J, Piazza C, Giudice M, De Maria G, Nicolai P. Shoulder disability after different selective neck dissections (levels II-IV versus levels II-V): a comparative study. Laryngoscope. 2005;1 15(2):259-63.

4. Watkins JP, Williams GB, Mascioli AA, Wan JY, Samant S. Shoulder function in patients undergoing selective neck dissection with or without radiation and chemotherapy. Head Neck. 2011;33(5):615-9.

5. Moore BA, Weber RS, Prieto V, El-Naggar A, Holsinger FC, Zhou X, et al. Lymph node metastases from cutaneous squamous cell carcinoma of the head and neck. Laryngoscope. 2005;115(9):1561-7.

6. Jambusaria-Pahlajani A, Kanetsky PA, Karia PS, Hwang WT, Gelfand JM, Whalen FM, et al. Evaluation of AJCC tumor staging for cutaneous squamous cell carcinoma and a proposed alternative tumor staging system. JAMA Dermatol. 2013;149(4):402-10.

7. National Cancer Institute. Common Terminology Criteria for Adverse Events (CTCAE) v4.0. 2010; Available from: http://evs.nci.nih.gov/ftp1/CTCAE/ About.html.

8. Edge S, Byrd DR, Compton CC, Fritz AG, Greene FL, Trotti A. American Joint Committee on Cancer (AJCC) Cancer Staging Manual. New York, NY: Springer; 2015.

9. Mendenhall WM, Parsons JT, Mendenhall NP, Million RR. T2-T4 carcinoma of the skin of the head and neck treated with radical irradiation. Int J Radiat Oncol Biol Phys. 1987;13(7):975-81.

10. Balamucki CJ, Mancuso AA, Amdur RJ, Kirwan JM, Morris CG, Flowers FP, et al. Skin carcinoma of the head and neck with perineural invasion. Am J Otolaryngol. 2012;33(4):447-54.

11. Chen AM, Grekin RC, Garcia J, Bucci MK, Margolis LW. Radiation therapy for cutaneous squamous cell carcinoma involving the parotid area lymph 
nodes: dose and volume considerations. Int J Radiat Oncol Biol Phys. 2007:69(5):1377-80.

12. NCCN Clinical Practice Guidelines in Oncology (NCCN Guidelines ${ }^{\circledR}$ : Squamous Cell Skin Cancer, Version 1.2015. Fort Washington: National Comprehensive Cancer Network; 2014 [updated October 24, 2014; cited 2015 April 6, 2015]; Available from: http://www.nccn.org/professionals/ physician_gls/pdf/squamous.pdf.

Submit your next manuscript to BioMed Central and take full advantage of:

- Convenient online submission

- Thorough peer review

- No space constraints or color figure charges

- Immediate publication on acceptance

- Inclusion in PubMed, CAS, Scopus and Google Scholar

- Research which is freely available for redistribution 